\title{
Magnesium Sulfate Versus Lidocaine for Attenuating Hemodynamic Response to Tracheal Intubation
}

\author{
Zeinab Hamed Sawan, Kamelia Ahmed Abaza, Ahmad Zyada, Ahmad Ezz El Din \\ Department of Anesthesia and Surgical Intensive care, Faculty of Medicine-Zagazig University. \\ *Corresponding Author: Ahmad Ezz El Din Muhammad, Mobile: +20 01014353330, Email:ahmedezz188@gmail.com
}

\begin{abstract}
Background: It is well recognized that the occurrence of hemodynamic responses in the form of rise in heart rate and blood pressure during and after laryngoscopy and endotracheal intubation mediated by sympathetic response, is a wellknown treat. Objective: The aim of the study was to evaluate effects of magnesium sulfate and lidocaine in attenuating hemodynamic response at a certain doses based on previous studies.

Patients and Methods: 76 patients were randomly divided into two groups (group M and group L) using computer generated randomization table, and induced by magnesium sulphate $(30 \mathrm{mg} \cdot \mathrm{kg}-1)$ or $2 \%$ lidocaine $(2 \mathrm{mg} \cdot \mathrm{kg}-1)$, infused in 3 minutes using syringe pump, after 3 minutes of pre-oxygenation, we proceeded for anesthetic induction by $2 \mathrm{mg} / \mathrm{kg}$ propofol and after loss of consciousness, $0.5 \mathrm{mg} / \mathrm{kg}$ atracurium (a muscle relaxant). All patients in both groups were intubated by the same anesthetist (the researcher) with direct laryngoscopy 3 minutes after administration of magnesium sulfate or lidocaine.

Results: There was statistically non-significant difference between the studied groups regarding age, gender, weight, height, body mass index, ASA, presence of diabetes or hypertension, systolic or diastolic blood pressure values baseline, mean arterial blood pressure and heart rate values baseline at a time range of 1 to 5 minutes, while, there was statistically significant difference between the studied groups regarding the same measurements at a time range of 5 to 15 minutes.
\end{abstract}

Conclusion: we conclude that magnesium sulphate is better alternative to lignocaine for attenuation of stress responses of laryngoscopy and intubation

Keywords: Hemodynamic response, Lidocaine, Magnesium sulfate

\section{INTRODUCTION}

It is well recognized that the occurrence of hemodynamic responses in the form of rise in heart rate and blood pressure during and after laryngoscopy and endotracheal intubation mediated by sympathetic response, is a well-known treat ${ }^{(\mathbf{1})}$.

The mechanism of the responses to laryngoscopy and orotracheal intubation are proposed to be by somatovisceral reflexes starts from proprioceptors at the base of the tongue, the epiglottis, hypopharynx, peritracheal area, and vocal cords. The efferent sympathetic outflow to the heart originates from the spinal cord between $\mathrm{T} 1$ and $\mathrm{T} 4$, and that to the adrenal medulla from between $\mathrm{T} 3$ and $\mathrm{L} 3{ }^{(2)}$.

The magnesium sulfate mechanism of action for hemodynamic response attenuation appears to result from the inhibition of catecholamine release from the adrenal medulla, maintains the plasma concentration of epinephrine practically unchanged, and also reduces the increased circulating norepinephrine when compared to that of a control group. It also has a systemic and coronary vasodilation effect by antagonizing calcium ion in vascular smooth muscle ${ }^{(\mathbf{3})}$.

Due to its inhibiting effects on release of catecholamines from adrenergic nerve endings and adrenal medulla, magnesium has been an option for minimizing adverse cardiovascular responses during laryngoscopy and intubation ${ }^{(4)}$.

As for lidocaine, when used systemically, it has an antagonistic action on sodium channels and NMDA receptors, reduces the release of substance $\mathrm{P}$, and has glycinergic action, which decreases the airway reactivity (5).

The aim of the study was to evaluate effects of magnesium sulfate and lidocaine in attenuating hemodynamic response at a certain doses based on previous studies.

\section{PATIENTS AND METHODS}

Site of study: This study was carried out in operating rooms of Zagazig University Hospitals.

Sample size: the sample size was calculated to be 76 (38 in each group).

\section{Inclusion criteria:}

1. ASA I or II.

2. Age: between $21-65$ years.

3. Gender: both male and female

4. Patients who are scheduled for elective surgery with orotracheal intubation.

5. BMI $<35 \mathrm{~kg} / \mathrm{m}^{2}$

Exclusion criteria:

1. Patient refusal.

2. Patients with contraindications or history of hypersensitivity to the study drugs.

3. Expected difficult intubation

Type of study: Randomized prospective comparative clinical study. All Patients were randomly divided into two groups (group $\mathrm{M}$ and group L) Using computer generated randomization table, each group consists of 38 patients. 
Parameters of the study included:

- All patients were visited a day before the surgery, examined for vital signs, chest condition, cardiac condition and difficult intubation was excluded.

- All patients were kept nil orally before the operation (8 $\mathrm{h}$ for fatty meal, $6 \mathrm{~h}$ for light meal and $2 \mathrm{~h}$ for clear fluids).

- Before entering the patient to operating room, standard monitoring was done with electrocardiogram (ECG), saturation of peripheral oxygen $\left(\mathrm{SpO}_{2}\right)$, noninvasive blood pressure (NIBP) (as baseline readings).

- IV line was inserted.

- Pre-oxygenation with $100 \%$ oxygen for 3 min was done before induction.

\section{Ethical approval:}

An approval of the study was obtained from Zagazig University academic and ethical committee. Every patient signed an informed written consent for acceptance of the operation.

\section{Collecting Data:}

From each patient the following data was collected:
- Demographic data (Name, age, gender, physical state ASA 1 and II).

- Medical and past surgical history.

- Hemodynamics (heart rate, Blood pressure).

- $\mathrm{SpO}_{2} \%$.

- Side effects.

\section{Statistical analysis}

Recorded data were analyzed using the statistical package for social sciences, version 20.0 (SPSS Inc., Chicago, Illinois, USA). Quantitative data were expressed as mean \pm standard deviation (SD). Qualitative data were expressed as frequency and percentage. Independentsamples t-test of significance was used when comparing between two means. Chi-square $\left(\mathrm{x}^{2}\right)$ test of significance was used in order to compare proportions between two qualitative parameters. The confidence interval was set to $95 \%$ and the margin of error accepted was set to $5 \%$. The $\mathrm{p}$-value was considered significant as the following: $\mathrm{P}$-value $<0.05$ was considered significant. P-value $<0.001$ was considered as highly significant. P-value $>0.05$ was considered insignificant.

\section{RESULTS}

There is statistically non-significant difference between the studied groups regarding age or gender (Table 1).

Table (1): Comparison between the studied groups regarding demographic characteristics

\begin{tabular}{|c|c|c|c|c|}
\hline \multirow{2}{*}{} & \multicolumn{2}{|c|}{ Study groups } & Test \\
\cline { 2 - 3 } & Lignocaine group & Magnesium sulphate group & \multirow{2}{*}{ X2/Z } & $\mathbf{p}$ \\
\cline { 2 - 5 } Gender: & $\mathrm{N}=38(\%)$ & $\mathrm{N}=38(\%)$ & & \\
Male & $19(50)$ & $23(60.5)$ & 0.852 & 0.356 \\
Female & $19(50)$ & $15(39.5)$ & & \\
\hline Age (years): & & & -0.572 & 0.567 \\
Mean \pm SD & $36.39 \pm 14.03$ & $38.11 \pm 13.08$ & & \\
Range & $18-65$ & $18-59$ & \\
\hline
\end{tabular}

There is significant difference between the studied groups regarding systolic blood pressure value at 5,10 and 15 minutes. Within each group, there is significant change in systolic blood pressure over time (Table 2).

Table (2): Comparison between the studied groups regarding systolic blood pressure readings over time

\begin{tabular}{|l|l|l|l|l|}
\hline \multirow{2}{*}{$\begin{array}{l}\text { Systolic } \\
\text { blood } \\
\text { pressure } \\
(\mathbf{m m H g})\end{array}$} & \multicolumn{1}{|c|}{ Study groups } & \multicolumn{2}{|c|}{ Test } & \multirow{2}{*}{ p } \\
\cline { 2 - 5 } & Lignocaine group & Magnesium sulphate group & & \\
\cline { 2 - 5 } Baseline & Mean $\mathbf{\text { SD }}$ & Mean $\mathbf{\text { SD }}$ & -1.371 & 0.175 \\
\hline At 1 minute & $126.26 \pm 11.71$ & $129.76 \pm 10.53$ & -1.18 & 0.242 \\
\hline At 2 minutes & $141.42 \pm 28.12$ & $155.37 \pm 18.38$ & -1.307 & 0.195 \\
\hline At 3 minutes & $137.32 \pm 19.14$ & $148.55 \pm 18.44$ & -0.335 & 0.739 \\
\hline At 4 minutes & $129.5 \pm 17.64$ & $138.74 \pm 17.84$ & 0.91 & 0.366 \\
\hline At 5 minutes & $121.29 \pm 16.72$ & $126.03 \pm 15.57$ & 2.08 & $0.041^{*}$ \\
\hline At 10 minutes & $130.32 \pm 16.38$ & $113.08 \pm 17.69$ & 3.373 & $0.001^{* *}$ \\
\hline At 15 minutes & $133.53 \pm 18.73$ & $116.53 \pm 19.15$ & 4.654 & $<0.001^{* *}$ \\
\hline P & $<0.001 * *$ & $113.18 \pm 19.37$ & & \\
\hline
\end{tabular}

There is significant difference between the studied groups regarding diastolic blood pressure (DBP) at 10 and 15 minutes. Within each group, there is significant change in DBP over time (Table 3). 
Table (3): Comparison between the studied groups regarding diastolic blood pressure readings over time

\begin{tabular}{|l|l|l|l|l|}
\hline \multirow{2}{*}{$\begin{array}{l}\text { Diastolic } \\
\text { blood } \\
\text { pressure } \\
(\mathbf{m m H g})\end{array}$} & \multicolumn{1}{|c|}{ Study groups } & \multicolumn{2}{c|}{ Test } & \multirow{2}{*}{ p } \\
\cline { 2 - 5 } & Lignocaine group & Magnesium sulphate group & & \\
\hline Baseline & $76.21 \pm 7.02$ & Mean \pm SD & & \\
\hline At 1 minute & $88.68 \pm 7.57$ & $75 \pm 8.56$ & 0.674 & 0.502 \\
\hline At 2 minutes & $86.37 \pm 7.19$ & $88.55 \pm 8.61$ & 0.071 & 0.944 \\
\hline At 3 minutes & $82.79 \pm 7.23$ & $85.18 \pm 7.9$ & 0.683 & 0.497 \\
\hline At 4 minutes & $79.84 \pm 7.91$ & $81.79 \pm 8.33$ & 0.559 & 0.578 \\
\hline At 5 minutes & $76.92 \pm 8.32$ & $76.84 \pm 8.71$ & 1.571 & 0.120 \\
\hline At 10 minutes & $83.66 \pm 9.37$ & $73.08 \pm 10.41$ & 1.777 & 0.08 \\
\hline At 15 minutes & $80.05 \pm 8.15$ & $72.53 \pm 8.1$ & 3.633 & $0.001^{* *}$ \\
\hline P & $<0.001 * *$ & $72.92 \pm 8.95$ & 5.541 & $<0.001^{* *}$ \\
\hline
\end{tabular}

There is significant difference between the studied groups regarding heart rate value at 5,10 and 15 minutes. Within each group, there is significant change in heart rate over time (Table 4).

Table (4): Comparison between the studied groups regarding heart rate readings over time

\begin{tabular}{|l|l|l|l|l|}
\hline \multirow{2}{*}{$\begin{array}{l}\text { Heart } \\
\text { rate (b/m) }\end{array}$} & \multicolumn{1}{|c|}{ Study groups } & \multicolumn{2}{c|}{ Test } \\
\cline { 2 - 5 } & Lignocaine group & Magnesium sulphate group & \multirow{2}{*}{ t } & \multirow{2}{*}{ p } \\
\cline { 2 - 5 } & Mean \pm SD & Mean \pm SD & 1.313 & 0.193 \\
\hline Baseline & $78.39 \pm 13.04$ & $74.84 \pm 10.41$ & 0.867 & 0.389 \\
\hline At 1 minute & $93.21 \pm 13.95$ & $90.61 \pm 11.18$ & 0.772 & 0.442 \\
\hline At 2 minutes & $88.87 \pm 13.76$ & $86.66 \pm 11.04$ & 1.05 & 0.297 \\
\hline At 3 minutes & $84.97 \pm 12.54$ & $82.23 \pm 12.67$ & 1.61 & 0.112 \\
\hline At 4 minutes & $82.34 \pm 12.67$ & $78.21 \pm 9.47$ & 2.199 & $0.031^{*}$ \\
\hline At 5 minutes & $79.71 \pm 11.18$ & $73.16 \pm 14.57$ & 4.873 & $<0.001^{* *}$ \\
\hline At 10 minutes & $82.47 \pm 10.17$ & $71.87 \pm 8.75$ & 6.746 & $<0.001^{* *}$ \\
\hline At 15 minutes & $85.74 \pm 10.06$ & $72.03 \pm 7.47$ & & \\
\hline P & $<0.001 * *$ & $<0.001 * *$ & & \\
\hline
\end{tabular}

There is significant difference between the studied groups regarding rate pressure product (RPP) values at 10 and 15 minutes. Within each group, there is non- significant change in RPP over time (Table 5).

Table (5): Comparison between the studied groups regarding RPP over time

\begin{tabular}{|l|l|l|l|l|l|l|}
\hline \multirow{2}{*}{ RPP } & \multicolumn{9}{|c|}{ Study groups } & \multicolumn{2}{c|}{ Test } \\
\cline { 2 - 6 } & Lignocaine group & \multicolumn{2}{|c|}{ Magnesium sulphate group } & \multirow{2}{*}{ Z } & \multirow{2}{*}{ p } \\
\cline { 2 - 7 } & Mean \pm SD & Median & Mean \pm SD & Median & & \\
\hline Baseline & $5486.24 \pm 3773.54$ & 7754 & $5889.87 \pm 3726.49$ & 7712 & -0.623 & 0.533 \\
\hline At 1 minute & $1399.89 \pm 265.04$ & 1415.5 & $1838.45 \pm 1719.14$ & 1453 & -0.935 & 0.35 \\
\hline At 2 minutes & $2391.74 \pm 2768.57$ & 1394 & $2597.29 \pm 2899.58$ & 1420 & -0.473 & 0.636 \\
\hline At 3 minutes & $3477.26 \pm 3504.03$ & 1383 & $3676.37 \pm 3636.26$ & 1337 & -0.083 & 0.934 \\
\hline At 4 minutes & $4238.63 \pm 3598.38$ & 1383 & $5437.87 \pm 3579.62$ & 7136 & -0.992 & 0.321 \\
\hline At 5 minutes & $5020.34 \pm 3593.92$ & 6776.5 & $6189.24 \pm 3114.49$ & 7039 & -0.888 & 0.374 \\
\hline At 10 minutes & $10799.89 \pm 2202.83$ & 10207.5 & $8419.34 \pm 1965.71$ & 11635.5 & -4.571 & $<0.001^{* *}$ \\
\hline At 15 minutes & $11520.29 \pm 2445.63$ & 7910 & $8201.16 \pm 1888.99$ & 7722 & -5.361 & $<0.001^{* *}$ \\
\hline P & 0.089 & 0.83 & & & \\
\hline
\end{tabular}

There is significant change between the studied groups regarding percent change in systolic blood pressure at 4,5 , 10 and 15 minutes (Table 6). 
Table (6): Comparison between the studied groups regarding percent change in systolic blood pressure readings over time

\begin{tabular}{|l|l|l|l|l|}
\hline \multirow{2}{*}{$\begin{array}{c}\text { \% change } \\
\text { in SBP }\end{array}$} & \multicolumn{1}{|c|}{ Study groups } & \multicolumn{2}{c|}{ Test } \\
\cline { 2 - 5 } & Lignocaine group & Magnesium sulphate group & \multirow{2}{*}{ Z } & \multirow{2}{*}{ p } \\
\cline { 2 - 5 } & Median (range) & Median (range) & -1.094 & 0.294 \\
\hline At 1 minute & $16.72(3.51-48.28)$ & $19.54(1.72-45.65)$ & -0.556 & 0.578 \\
\hline At 2 minutes & $12.87(-89-41.38)$ & $13.31(-0.86-42.75)$ & -0.727 & 0.467 \\
\hline At 3 minutes & $7.44(-20.97-33.33)$ & $6.34(-15.75-29.01)$ & -2.104 & $0.035^{*}$ \\
\hline At 4 minutes & $1.1(-23.39-26.95)$ & $-1.89(-23.53-13.04)$ & -3.059 & $0.002^{*}$ \\
\hline At 5 minutes & $-4.7(-25-20.16)$ & $-12.71(-34.62-4.24)$ & -3.927 & $<0.001^{* *}$ \\
\hline At 10 minutes & $3.48(-15-25.62)$ & $-11.54(-30.71-24.79)$ & -4.935 & $<0.001^{* *}$ \\
\hline At 15 minutes & $8.69(-19.09-31.4)$ & $-16.8(-39.72-25.86)$ & & \\
\hline
\end{tabular}

There is significant difference between the studied groups regarding percent change in DBP at 10 and 15 minutes (Table 7).

Table (7): Comparison between the studied groups regarding percent change in diastolic blood pressure readings over time

\begin{tabular}{|l|l|l|l|l|}
\hline \multirow{2}{*}{$\begin{array}{c}\text { \% change } \\
\text { in DBP }\end{array}$} & \multicolumn{1}{|c|}{ Study groups } & \multicolumn{2}{c|}{ Test } \\
\cline { 2 - 3 } & Lignocaine group & Magnesium sulphate group & \multirow{2}{*}{ Z } & \multirow{2}{*}{ p } \\
\cline { 2 - 5 } & Median (range) & Median (range) & -1.112 & 0.266 \\
\hline At 1 minute & $14.95(3.61-46.15)$ & $17.43(4.63-36.92)$ & -0.317 & 0.751 \\
\hline At 2 minutes & $13.53(-4.82-41.54)$ & $14.21(2.53-28.79)$ & -0.062 & 0.950 \\
\hline At 3 minutes & $9.8(-8.43-30.77)$ & $7.68(-4.23-30.77)$ & -0.889 & 0.374 \\
\hline At 4 minutes & $4.39(-13.92-32.31)$ & $2.96(-23.94-24.24)$ & -1.149 & 0.25 \\
\hline At 5 minutes & $0(-17.86-32.31)$ & $-0.55(-29.23-23.19)$ & -2.13 & $0.033^{*}$ \\
\hline At 10 minutes & $7.54(-17.39-29.23)$ & $-3.16(-32.92-33.33)$ & -3.6 & $<0.001^{* *}$ \\
\hline At 15 minutes & $7.64(-25.64-38.46)$ & $-3.74(-25.61-26.15)$ & & \\
\hline
\end{tabular}

There is significant difference between the studied groups regarding percent change in heart rate at 10 and 15 minutes (Table 8).

Table (8): Comparison between the studied groups regarding percent change in heart rate readings over

\begin{tabular}{|l|l|l|l|l|}
\hline \multirow{2}{*}{$\begin{array}{c}\text { \% change } \\
\text { in HR }\end{array}$} & \multicolumn{1}{|c|}{ Study groups } & \multicolumn{2}{c|}{ Test } \\
\cline { 2 - 5 } & Lignocaine group & Magnesium sulphate group & \multirow{2}{*}{$\mathrm{Z}$} & \multirow{2}{*}{ p } \\
\cline { 2 - 5 } & Median (range) & Median (range) & & \\
\hline At 1 minute & $18.24(7.85-52.78)$ & $19.89(4-49.33)$ & -0.977 & 0.319 \\
\hline At 2 minutes & $13.61(-6.82-34.720$ & $15.02(-2-41.33)$ & -0.784 & 0.433 \\
\hline At 3 minutes & $8.65(-12.5-33.3)$ & $7.95(-7.87-28.13)$ & -0.514 & 0.607 \\
\hline At 4 minutes & $5.88(-13.64-22.22)$ & $4.58(-22.47-23.44)$ & -0.104 & 0.917 \\
\hline At 5 minutes & $1.52(-13.6-19.44)$ & $0.62(91.75-18.67)$ & -0.67 & 0.503 \\
\hline At 10 minutes & $5.86(-21.6-26.15)$ & $-6.56(-31.4-30.51)$ & -2.597 & $0.009^{*}$ \\
\hline At 15 minutes & $12.06(-19.12-37.5)$ & $-4.23(-31.71-30.51)$ & -3.351 & $0.001^{* *}$ \\
\hline
\end{tabular}

There is significant difference between the studied groups regarding percent change in RPP at 10 and 15 minutes (Table 9). 
https://ejhm.journals.ekb.eg/

Table (9): Comparison between the studied groups regarding percent change in RPP over time

\begin{tabular}{|l|l|l|l|l|}
\multirow{2}{*}{$\begin{array}{c}\text { \% change } \\
\text { in RPP }\end{array}$} & Study groups & \multicolumn{2}{|c|}{ Test } \\
\cline { 2 - 5 } & Lignocaine group & Magnesium sulphate group & \multirow{2}{*}{ Z } & \multirow{2}{*}{ p } \\
\cline { 2 - 5 } & Median (range) & Median (range) & -0.603 & 0.547 \\
\hline At 1 minute & $-83.24(-87.58-74.19)$ & $-83.32(-88.15-77.29)$ & -0.062 & 0.95 \\
\hline At 2 minutes & $11.98(-88.86-749.31)$ & $5.08(-89.41-63.41)$ & 582 & 61 \\
\hline 3 minutes & $3(-88.73-591.66)$ & $1(-89.04-43.76)$ & 249 & 03 \\
\hline $\mathbf{4}$ minutes & $1(-88.79-795.63)$ & $54(-89.05-740.76)$ & 364 & 16 \\
\hline $\mathbf{5}$ minutes & $35(-89.39-751.56)$ & $3(-38.5-763.62)$ & 431 & $15^{*}$ \\
\hline $\mathbf{1 0}$ minutes & $36(-18.15-1332.31)$ & $11(-39.14-826.58)$ & 878 & $04^{*}$ \\
\hline $\mathbf{1 5}$ minutes & $47(-30.58-1367.69)$ & $81(-40.02-763.36)$ & \multicolumn{2}{|c|}{} \\
\hline
\end{tabular}

\section{DISSCUSION}

There is statistically non-significant difference between the studied groups regarding age, gender, weight, height, body mass index, ASA and presence of diabetes or hypertension. There is statistically nonsignificant difference between the studied groups regarding systolic blood pressure values baseline, at 1,2, 3 and 4 minutes. However, there is significant difference between them regarding systolic blood pressure value at 5, 10 and 15 minutes. Within each group, there is significant change in systolic blood pressure over time in the lidocaine group as compared to the magnesium sulphate group. This finding was in accordance with Padmawar and Patil (1) who concluded that systolic blood pressure in both the groups after premedication and after study drug showed insignificant differences. In lignocaine group SBP increased after intubation. Average rise was $22.84 \mathrm{mmHg}$ at $1 \mathrm{~min}$ interval. Many (44\%) of the patients showed rise in the range of 21-30 $\mathrm{mm} \mathrm{Hg}$ from baseline. This raised SBP did not come to baseline and remained significantly raised even 5 minutes after intubation. In $\mathrm{MgSO}_{4}$ group SBP increased significantly only at $1 \mathrm{~min}$ after intubation. Average rise was $6.64 \mathrm{~mm} \mathrm{Hg}$ at $1 \mathrm{~min}$ interval and majority (90\%) of the patients showed rise in the range of $0-10 \mathrm{~mm} \mathrm{Hg}$ from baseline. This rise in SBP came to baseline value towards 5 minutes and even $50 \%$ of the patients showed decline in it from baseline. Also in accordance with the present study Nooraei et $\boldsymbol{a l} .{ }^{(3)}$ who compared intravenous magnesium sulfate and lidocaine on hemodynamic variables following direct laryngoscopy and intubation in elective surgery patients. They found that $\mathrm{In} \mathrm{MgSO}_{4}$ group SBP increases significantly only at $1 \mathrm{~min}$ after intubation. Average rise was $6.64 \mathrm{~mm} \mathrm{Hg}$ at $1 \mathrm{~min}$ interval and majority (90\%) of the patients showed rise in the range of $0-10 \mathrm{~mm} \mathrm{Hg}$ from baseline. This rise in SBP came to baseline value towards 5 minutes and even $50 \%$ of the patients showed decline in it from baseline. In a prospective study, Mendonça et al. ${ }^{(6)}$ compared effects of lidocaine and magnesium sulfate in attenuating hemodynamic response to tracheal intubation on patients scheduled for elective surgery with orotracheal intubation (OTI) were assessed for eligibility, between September and November 2014 at the Hospital de Base do Distrito Federal. They concluded an increased SBP in both groups after laryngoscopy compared to baseline. Group $M$ had a statistically significant increase in SBP $(\mathrm{p}=0.018)$ and DBP $(\mathrm{p}=0.0467)$ post-OTI, but of little clinical importance. There were higher pressure values in the $3^{\text {rd }}$ and $6^{\text {th }}$ minutes post-OTI in group $\mathrm{M}$, but without statistical significance. After this period, both groups showed a gradual reduction in blood pressure values.

As regard to diastolic blood pressure, the present study showed statistically non-significant difference between the studied groups regarding diastolic blood pressure values baseline, at 1, 2, 3,4 or 5 minutes. On the other hand, there is significant difference between them regarding DBP at 10 and 15 minutes. Within each group, there is significant change in diastolic blood pressure over time. This finding was in accordance with Padmawar and Patil (1) who concluded that diastolic blood pressure in both the groups before and after premedication and after drug showed insignificant differences. In lignocaine group DBP increased after intubation and average rise was $14.12 \mathrm{~mm} \mathrm{Hg}$ at $1 \mathrm{~min}$ interval. The majority (56\%) of the patients showed rise in the range of 11-20 $\mathrm{mm} \mathrm{Hg}$ from baseline. This raise in DBP does not come to baseline and remains significantly raised even 5 minutes after intubation. While in $\mathrm{MgSO}_{4}$ group DBP increased significantly only at $1 \mathrm{~min}$ after intubation and average rise was $6.24 \mathrm{mmHg}$ at $1 \mathrm{~min}$ interval. The majority (92\%) of the patients showed rise in the range of $0-10 \mathrm{~mm} \mathrm{Hg}$ from baseline. This raise in DBP came to baseline value towards 3 minute and even $30 \%$ of the patients showed decline in it from baseline.

Also in accordance with the present study, Nooraei et al. ${ }^{(3)}$ found that diastolic blood pressure in the lidocaine group also showed an increase, but the difference between the baseline diastolic pressure and blood pressure measured 5 minutes after intubation was not statistically significant. In a prospective study, Mendonca et al. ${ }^{\left({ }^{(6)}\right.}$ found that there was an increase in DBP in both groups after laryngoscopy compared to baseline. Group $M$ had a statistically significant increase in SBP ( $\mathrm{p}=0.018)$ and DBP ( $=0.0467)$ post-OTI, but of little clinical importance. There were higher pressure values in the $3^{\text {rd }}$ and $6^{\text {th }}$ minutes post-OTI in group $\mathrm{M}$, but without statistical significance. After this period, 
both groups showed a gradual reduction in blood pressure values.

As regard to heart rate, the present study showed that there was statistically non-significant difference between the studied groups regarding heart rate values baseline, at 1, 2, 3 and 4 minutes. However, there was significant difference between them regarding heart rate value at 5, 10 and 15 minutes. Within each group, there was significant change in heart rate over time.

This finding only at time points $1,2,3$ and 4 minutes was in accordance with Mendonca et al. ${ }^{(6)}$ who concluded that there was a trend to higher HR values in the continuous infusion post-pump time (CIP end) in group $\mathrm{M}$, also with no statistical difference. There was no statistical difference in HR values at time points. There was an increase in heart rate after laryngoscopy in both groups, followed by gradual decline.

Nooraei et al. ${ }^{(3)}$ made comparison of heart rates between the two groups that showed an almost equal increase in heart rate in both groups in the first minute after intubation, and no significant difference was found between the two groups in this regard. But, at the $2^{\text {nd }}, 3^{\text {rd }}$, and $4^{\text {th }}$ minutes, heart rate was significantly lower in the lidocaine group, and no significant difference existed at 5 minutes.

Padmawar and Patil ${ }^{(1)}$ concluded that heart rate in both groups after premedication showed insignificant differences. In lignocaine group HR decreased after premedication, but it was not increased after lignocaine administration. However average rise in $\mathrm{HR}$ at $1 \mathrm{~min}$ after intubation was 22.58 beats. Majority $(70 \%)$ of the patients showed rise in $\mathrm{HR}$ in the range of 21-30 beats/min from baseline. This rise in HR did not come to baseline even at 5 minutes after intubation. While in magnesium sulphate group HR decreased after premedication, and it was increased after magnesium sulphate administration but rise in HR was insignificant. Average rise in $\mathrm{HR}$ at $1 \mathrm{~min}$ after intubation was 10.2 beats. Majority $(68 \%)$ of the patients showed rise in HR in the range of $0-10$ beats/min from baseline and HR normalizes up to $5 \mathrm{~min}$ after intubation.

As regard rate pressure product (RPP) the present study showed that there was statistically non-significant difference between the studied groups regarding RPP values baseline, at 1, 2, 3, 4 and 5 minutes. However there was significant difference between them regarding it at 10 and 15 minutes. Within each group, there was non-significant change in RPP over time. Padmawar and Patil ${ }^{(1)}$ found that rate pressure product in both the groups before and after premedication showed insignificant differences. On intergroup comparison between lignocaine and $\mathrm{MgSO}_{4}$ group, it was noted that RPP increased significantly in lignocaine group as compared with $\mathrm{MgSO}_{4}$ group at 1, 3, 5 minutes after intubation. RPP rises in both the groups but RPP came towards baseline at 3 minutes after intubation in $\mathrm{MgSO}_{4}$ group but that was not the case with lignocaine group.

\section{CONCLUSION}

The present study revealed that magnesium sulphate provide fairly good and sustained control over hemodynamic responses to the stress of laryngoscopy and intubation and is significantly better than lignocaine, so we conclude that magnesium sulphate is better alternative to lignocaine for attenuation of stress responses of laryngoscopy and intubation.

\section{REFERENCES}

1. Padmawar S, Patil M (2016): A Comparative study of $2 \%$ lignocaine vs $50 \%$ magnesium sulphate for attenuation of stress responses to laryngoscopy and endotracheal intubation. Intern J Contemp Med Res., 16: 2317 - 2320.

2. Arora S, Kulkarni A, Bhargava A (2015): Attenuation of hemodynamic response to laryngoscopy and orotracheal intubation using intravenous clonidine. J Anaesthesiol Clin Pharmacol., 13: 110-4.

3. Nooraei N, Dehkordi M, Radpay B et al. (2013): Effects of intravenous magnesium sulfate and lidocaine on hemodynamic variables following direct laryngoscopy and intubation in elective surgery patients. Tanaffos., 12: 57-63.

4. Shin Y, Choi S, Jeong H et al. (2011): Evaluation of dose effects of magnesium sulfate on rocuronium injection pain and hemodynamic changes by laryngoscopy and endotracheal intubation. Korean J Anesthesiol., 3: 329333.

5. Min J, Chai H, Kim Y et al. (2010): Attenuation of hemodynamic responses to laryngoscopy and tracheal intubation during rapid sequence induction: remifentanil vs. lidocaine with esmolol. Minerva Anestesiol., 8: 188192.

6. Mendonça F, de Queiroz L, Guimarães C et al. (2017): Effects of lidocaine and magnesium sulfate in attenuating hemodynamic response to tracheal intubation: singlecenter, prospective, double-blind, randomized study. Rev Bras Anestesiol., 67(1):50-56. 